\title{
O Inferno: Algumas Reflexões Sobre a Moral e a Deontologia
}

\author{
The Hell: Some Reflexions on Moral and Deontology
}

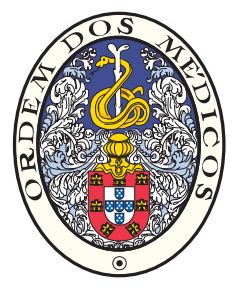

Nuno FÉLIX DA COSTA ${ }^{1,2}$

Acta Med Port 2015 Mar-Apr;28(2):271-274

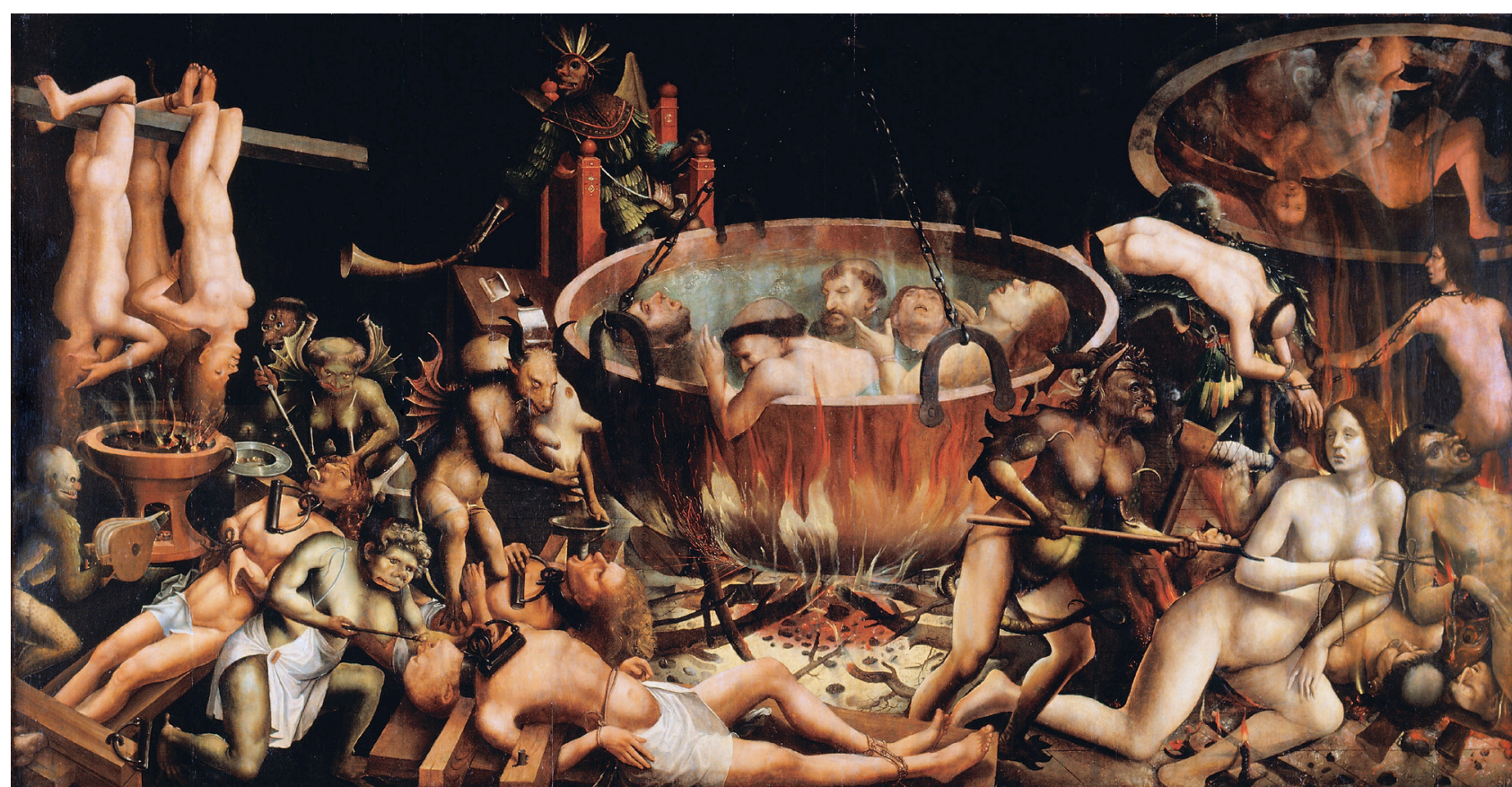

Figura 1 - "Inferno", Autor desconhecido, século XVI (c. 1510-1520), Óleo sobre madeira de carvalho, 119 x 217,5 cm. Proveniência: Conventos extintos, 1834. Museu Nacional de Arte Antiga, inv. 432 Pint.

Palavras-chave: Ética; Moral; Pintura.

Keywords: Ethics; Morals; Paintings.

Esta representação do Inferno de um autor anónimo do princípio do século XVI tem sido salientada como especialmente caraterizadora da moral nacional do tempo da Expansão (Fig. 1). ${ }^{1}$ Nem sempre a determinação dos comportamentos decorre da noção de Bem e de Mal, antes de uma avaliação das vantagens, das antecipações do gozo e do alívio e, por outro lado, dos riscos e dos custos da transgressão das regras. A interiorização dos valores morais é sempre parcial e, em muitas pessoas normais nunca chega a estruturar-se de uma forma explícita. A ausência da representação do Bem nesta obra fez alguns críticos supor que integraria um tríptico que, provavelmente, incluiria o Purgatório. ${ }^{2}$ Talvez mais que a noção de Bem, a noção de Mal é contingente da cultura e da época, ${ }^{3}$ neste sentido podendo revelar o que as pessoas pensam do inconveniente, do condenável, do repulsivo, do perverso, mas, também das respetivas personificações, quer os virtuosos e os que se condenam quer, por outro lado, os agentes que alicerçam o Bem e o implementam, as divindades e os anjos, em tensão com os agentes do Mal, Satanás e os demónios. Neste Inferno, Satanás surge numa posição presidencial, sentado num trono atrás do caldeirão onde ardem três monges e duas mulheres (Fig. 2). Está representado por uma figura exótica que cruza elementos da cultura tupinambá do Brasil recém-descoberto, vestido com uma armadura medieval militar coberta de penas. Também os diabos que torturam os pecadores são representados como hermafroditas de pele escura e feições negróides o que é interpretado numa linha etnocêntrica de atribuir malignidade ao Outro (Fig. 3). Assim, aparece apenas representado o pólo negativo dos comportamentos pecaminosos, mas, repare-se, os pecadores são os cristãos, novos ou velhos, de pele branca, não os demónios de pele escura personificados pelos índios. É-lhes atribuída uma natureza diferente da dos cristãos e

1. Psiquiatra.

2. Professor de Psicologia Médica. Faculdade de Medicina. Universidade de Lisboa. Lisboa. Portugal.

Recebido: 15 de Outubro de 2014 - Aceite: 15 de Outubro de 2014 | Copyright @ Ordem dos Médicos 2015 
conferido o poder não displicente de os torturar. Contudo, a ordem moral que parecem defender é a católica e, não estando representada nenhuma alusão ao Bem, não sabemos que valor é atribuído aos que castigam o Mal. Lembremos, a propósito, quanto as técnicas de tortura figuradas coincidem com as da Inquisição da Contra-Reforma cujos agentes eram monges beneditinos. De resto, esta obra teria sido encomendada por clientes conventuais e escondida no acervo do Convento de S. Bento da Saúde onde foi redescoberta em 1834 e transferida para o Museu de Arte Antiga. Ironicamente, terá sido o seu conteúdo heterodoxo que levou a que fosse escondida escapando à destruição pela censura da Inquisição.

De certa forma, a riqueza e a pluralidade de leituras constitui uma das dimensões da avaliação da qualidade de qualquer obra de arte, não apenas plástica, já que traduzem um resíduo de significações que persistentemente escapam a uma formulação racional ou redutora. Provavelmente existem diferentes mecanismos pelos quais as obras de arte nos perturbam e esta vivência integra o sentimento estético que elas desencadeiam em nós. Não tem que ser necessariamente agradável ou desagradável, mas deverá acrescentar, com a sua idiossincrática representação da verdade, algum valor à nossa consciência das coisas. O que nesta obra nos inquieta não percebemos se é a redundância da toada moralista tão pretensamente aterrorizadora, se o vazio em que são deixados os comportamentos alternativos ao pecado como se a mensagem moralizadora não valesse pelos seus valores positivos ou estes não fossem suficientemente fortes para se imporem interiorizados como princípios organizadores da ação e, assim, o resultado sobre nós de tal sistema moral fosse, sobretudo, a inibição da ação, o bloqueio das forças positivas e negativas a montante do comportamento numa tensão que não se resolve senão numa descarga catártica. Enquanto, na época, a moral assentava na pressão da comunidade próxima para a conformidade com as regras, hoje, ela perdeu o

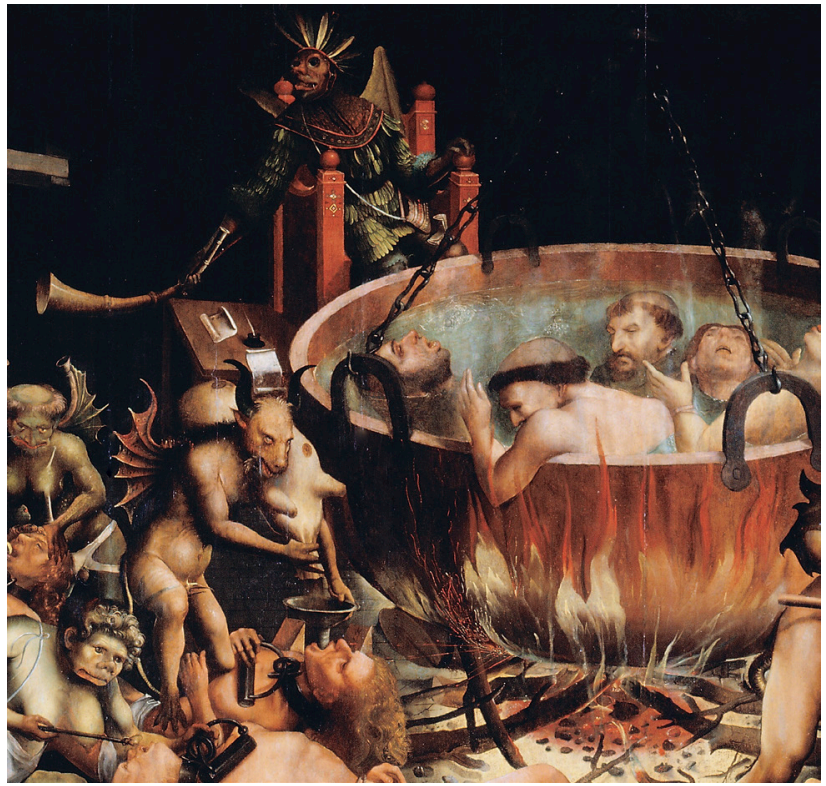

Figura 2 - Pormenor da figura de "Satanás" rosto diluída numa entidade planetária globalizada da qual emerge uma ética hedonista e individualista, mas mais capaz, em geral, de uma estruturação cognitiva racional no sentido da interiorização dos princípios morais. Contudo, o impulso para a conformidade radica, na maior parte das pessoas e na maior parte das situações, de um cálculo de vantagens e inconvenientes quando não de impulsos pouco racionais seja na intimidade das decisões individuais, na relação com o outro ou a nível das decisões de grupo nos grandes sistemas sociais e políticos. Tem uma dimensão estética, a moral, no sentido próximo da harmonia das formas, isto é, a riqueza com que os elementos da obra se reconfiguram fazendo aparecer uma visão surpreendente e enriquecida da realidade. Da mesma forma, os comportamentos engrenam numa dialética, digamos, histórica, a qualquer um dos níveis mencionados, e favorecem-na ou antagonizam-na.

No canto superior direito, um demónio negro carrega aos ombros um corpo inerte que tem sido identificado como de um monge; é seguido por um jovem amarrado pelo pescoço ao monge no que parece ser uma alusão à homossexualidade. Também no primeiro plano a beleza explícita da mulher que outro demónio atiça com uma lança. Está acorrentada a um amante, ambos recostados no corpo jazente de outro monge entre ambos. Ela olha-nos um pouco de esguelha, mas sem o ar desesperado do companheiro. Igualmente, dentro do caldeirão central, uma mulher e quatro homens dos quais três são monges. A representação destes condenados por delitos sexuais mostra bem como a moral sexual da época se infiltrava na intimidade dos crentes de uma forma que hoje repudiaríamos. Da mesma forma, a gula do bêbedo torturado por outro demónio com a ingestão forçada de vinho e, em paralelo, a avareza do usuário obrigado a engolir moedas de ouro. Hoje, tendemos a uma clara distinção entre a esfera privada na qual respeitamos a liberdade individual de cada pessoa se auto-construir, e uma normatividade nas condutas sociais

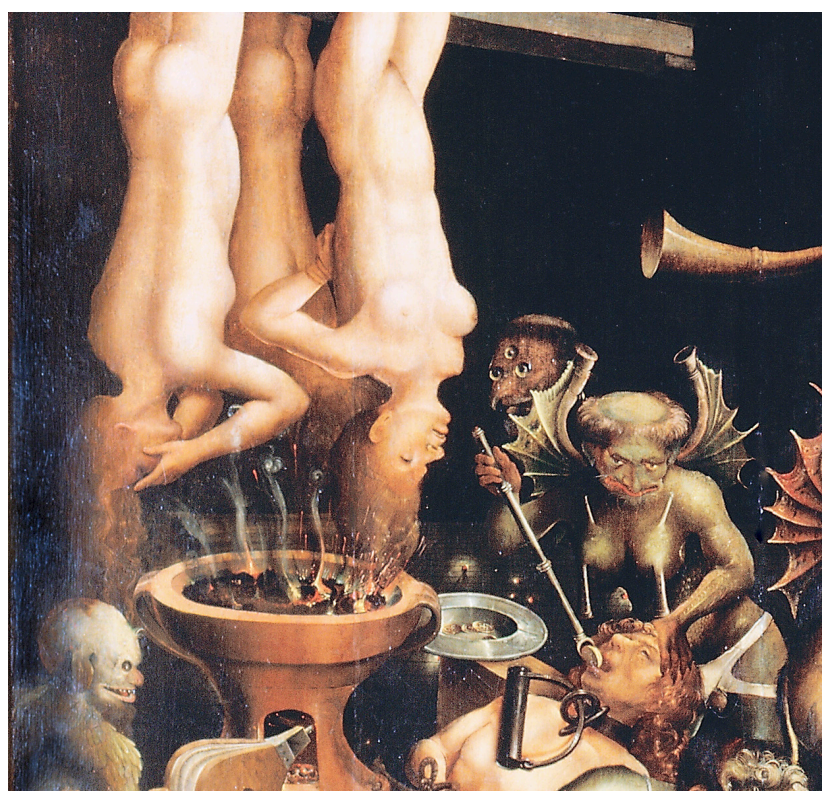

Figura 3 - Pormenor "Diabos e Pecadores" 
nas quais reprimimos os comportamentos que afetam o outro ou o grupo. A perspetiva que mantemos em relação ao que se designava por pecado é menos maniqueísta e mais contextualizada, isto é, os comportamentos desviantes ou anti-sociais são julgados pelas consequências numa lógica racional da capacidade da pessoa controlar a impulsividade e não na lógica de infrações a um catálogo de vícios. A abundância de religiosos entre os pecadores pode relacionar-se com uma função apologética e moralizadora da obra junto dos monges que com ela conviveriam; visaria manter viva a ameaça e o medo da tortura lembrando quanto o sexo, o dinheiro, a vaidade, a gula se associam a um caminho irremediavelmente contrário à virtude. Talvez, também considerar que à maior riqueza espiritual e material dos monges corresponde uma maior responsabilidade moral, logo uma justiça mais inclemente. Assim descontextualizado no museu a leitura que fazemos da sobre-representação dos monges entre os pecadores no inferno afigura-se iconoclasta. Podemos discutir se o valor de uma obra se sustenta na sua qualidade estética como se constituísse um universo fechado com os seus próprios critérios e valores ou se o seu enquadramento na biografia do autor, da sua cultura e da sua circunstância, de um lado enriquecem a leitura, do outro, relativizam o seu valor.

A representação da faculdade de julgar os humanos, e de julgar a própria Igreja representada pelos monges, surge, nesta obra, personificada nos demónios hermafroditas. Uma situação médica rara dependente da exposição intra-uterina do embrião a um padrão hormonal atípico, uma regressão do ponto de vista da filogénese da sexualidade, faz pensar numa espécie de exigência de neutralidade sexual como condição de isenção nas disputas entre géneros numa época em que as diferenças entre os respetivos papéis eram muito mais acentuadas a todos os níveis. Desde o apogeu do feminismo nos finais do século passado, assistimos a uma suavização do seu radicalismo provavelmente em relação com efetivas aquisições sociais em termos da atenuação das suas desvantagens de género. A fórmula feminista mais radical repudia qualquer forma de patriarcado, incluindo o papel de fornecedor do gâmeta masculino ao embrião no quadro amoroso como o momento inaugural da dominação. Advoga a criação de ilhas de total domínio feminino onde a expressão da mulher seja possível em todo o seu potencial, de certa forma, um sistema de domínio simétrico ou, porventura, mais sexista do que o patriarcado que assim propõem combater. A discriminação de género é tão repulsiva no plano moral como inestética e intolerável, seja qual for o seu enquadramento ideológico ou religioso. Hoje, que temos recuo histórico para avaliarmos as suas consequências, estão significativamente adquiridas em largos setores da população a infundamentação e o mau gosto da subjugação tanto feminina como de qualquer grupo na base do preconceito, tem menos impacto politicamente correto as suas propostas, algumas de contorno caricato. Uma fórmula mais poderosa de ultrapassar os constrangimentos biológicos de género seria a hermafroditização hormonal ou cirúrgica da espécie, como na presente obra.
Em qualquer caso a representação da nudez, se marca a diferença de géneros, não é, por si, uma marca de discriminação no sentido de não podermos falar de humano sem aludir a 'mulher' e a 'homem', termos que dificilmente poderão ser apagados dos diversos discursos que a humanidade produz (jurídico, literário, poético, plástico, político, etc.) conforme pretendem algumas correntes feministas; o que faz sentido é que a democratização elimine o preconceito, a discriminação e a subjugação em qualquer dos géneros.

O Purgatório, como local de expiação e de purificação pelo fogo, representaria a esperança ausente para os condenados ao Inferno. Hoje temos alguma dificuldade em julgar o Bem e o Mal fora de uma lógica sistémica. Focamos o valor intrínseco dos comportamentos, as suas intenções ou as suas consequências, tendemos a privilegiar o âmbito que o comportamento toma ou pretende tomar, mais do que a sua catalogação num inventário de transgressões a um código qualquer. Este poderá demarcar pessoas muito virtuosas que não apareceriam a ferver nos caldeirões do Inferno porque viveram bloqueadas no terror da tortura pelos demónios hermafroditas, mas pouco ou nada terão feito de meritório pela humanidade, enquanto inúmeros pecadores foram responsáveis por obras de grande mérito artístico, social, político, moral, etc. A deontologia médica obriga-se a um código hipocrático essencialmente simples que rege a intervenção do médico junto de alguém que sofre e lhe pede ajuda. Muitas perspetivas da ética filosófica usam situações médicas para ilustrar conflitos de valores e discuti-los no plano hipotético. Se alguns valores mantém um caráter absoluto, outros como o sigilo, são ameaçados pelas novas condições em que a profissão é exercida e pela intrusão de diversos profissionais no circuito de informação médico-doente com interesses que lhes são estranhos. O médico é frequentemente colocado em situações de uma deontologia pluralista em que deve considerar os vários vectores em que tem lugar a sua intervenção e que condicionam o acesso e a utilização dos recursos terapêuticos. Contudo, o gestionismo, se define o âmbito dos recursos disponíveis a nível organizacional, não pode interferir na sua prescrição nem na relação do médico com o seu doente. Nesta representação do Inferno não aparecem médicos - e na do Paraíso?

\section{AGRADECIMENTOS}

A Acta Médica Portuguesa e a Ordem dos Médicos agradecem ao Museu Nacional de Arte Antiga em Lisboa a gentil cedência dos direitos de reprodução deste quadro e a oportunidade de o divulgar.

\section{CONFLITOS DE INTERESSE}

$O$ autor nega qualquer conflito de interesses.

\section{FONTES DE FINANCIAMENTO}

O autor não recebeu nenhum financiamento para a escrita do artigo. 


\section{REFERÊNCIAS}

1. Markl D. Introdução ao estudo do "Inferno"do Museu Nacional de Arte Antiga. In: Boletim Cultural Póvoa de Varzim, vol. XXVI, n² 2. Póvoa de Varzim: Câmara Municipal de Póvoa de Varzim; 1989.

2. Mourão C. O julgamento das almas - pintura quinhentista da Escola Portuguesa do Museu Nacional de Arte Antiga. In: Boletim Cultural da
Assembleia Municipal de Lisboa. Lisboa: Câmara Municipal de Lisboa 1999.

3. Porfírio JL. Inferno - Museu Nacional de Arte Antiga, Lisboa. Lisboa: Edições Inapa; 1999. 
Nuno FÉLIX DA COSTA

\section{O Inferno: Algumas Reflexões Sobre a Moral e a Deontologia}

Acta Med Port 2015:28:271-274

Publicado pela Acta Médica Portuguesa, a Revista Científica da Ordem dos Médicos

Av. Almirante Gago Coutinho, 151

1749-084 Lisboa, Portugal.

Tel: +351218428 215

E-mail: submissao@actamedicaportuguesa.com

www.actamedicaportuguesa.com

ISSN:0870-399X | e-ISSN: 1646-0758

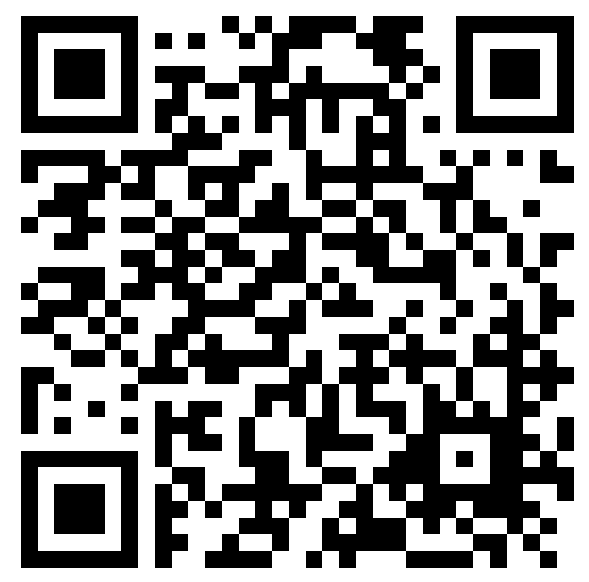

